\title{
SIMULASI BERKENDARA LALU LINTAS DENGAN MEDIA BARANG BEKAS UNTUK MENINGKATKAN DISIPLIN SEJAK USIA DINI DI TK QILPI AL JIHAD SURABAYA
}

\author{
${ }^{1}$ Siti Nur Hidayati, ${ }^{2}$ Muchamad Arif, ${ }^{3}$ Varia Virdania Virdaus, ${ }^{4}$ Andini Dwi Arumsari \\ ${ }^{1,3,4}$ Fakultas Keguruan dan Ilmu Pendidikan, Universitas Narotama \\ ${ }^{2}$ Fakultas Ekonomi dan Bisnis, Universitas Narotama \\ $\underline{1}$ sitinurhidayatihidayati@gmail.com
}

\begin{abstract}
ABSTRAK
Penelitian ini bertujuan untuk mengetahui keefektifitasan simulasi berkendara lalu lintas di TK Qilpi Al Jihad Surabaya. Penulis menggunakan metode deskriptif kualitatif. Penulis fokus bagaimana menerapkan simulasi berkendara lalu lintas dengan media barang bekas untuk meningkatkan disiplin pada anak sejak usia dini. Penulis melakukan observasi selama 4x pertemuan. Setiap pertemuan mereka memainkan peran yang berbeda namun dengan isi materi yang sama. Media bahan bekas yang dipakai sudah tersedia di sekolah dan sudah disesuaikan dengan materi yang diajarkan. Subjek penelitian adalah TK Qilpi Al Jihad Surabaya yang berjumlah 14 siswa. Seluruh siswa menggunakan media dari bahan bekas di setiap pertemuan selama 30 menit. Hasil penelitian menunjukkan bahwa media pembelajaran melalui media bahan bekas yang bervariasi dalam suatu pembelajaran akan membuat anak-anak semakin bersemangat dan antusias untuk belajar karena tidak membosankan. Namun, bagi anak-anak yang kurang memahami rambu-rambu dan peraturan lalu lintas yang telah dijelaskan oleh guru, mereka akan mengalami kesulitan dan kebingungan.
\end{abstract}

Kata Kunci: simulasi berkendara, melatih kedisiplinan anak usia dini, motorik kasar

\begin{abstract}
This study aims to determine the effectiveness of traffic driving simulations at Qilpi Al Jihad Kindergarten in Surabaya. The author uses a qualitative descriptive method. The author focuses on applying traffic driving simulations with used media to improve discipline in children from an early age. The author observes 4 times meetings. Each of their meetings plays a different role but with the same content. Media used materials used are available at school and have been adapted to the material being taught. The research subjects were the Qilpi Al Jihad Surabaya Kindergarten which numbered 14 students. All students use media from used materials at each meeting for 30 minutes. The results showed that learning media through varied media used materials will make children more enthusiastic and enthusiastic to learn because it is not boring. However, for children who do not understand the traffic signs and regulations that have been explained by the teacher, they will experience difficulties and confusion.
\end{abstract}

Keywords: driving simulation, training discipline in early childhood, gross motoric 


\section{PENDAHULUAN}

Tingkat kecelakaan lalu lintas selalu meningkat pada setiap tahunnya. Salah satu faktor utama terhadap kecelakaan tersebut adalah pengemudi yang tidak paham akan rambu-rambu lalu lintas atau dengan sengaja melanggar peraturan lalu lintas. Oleh sebab itu, pembelajaran tentang rambu-rambu lalu lintas harus dipelajari sedini mungkin agar anak usia dini dapat memulai menanamkan jiwa positif terhadap penggunaan kendaraan dan rambu-rambu lalu lintas pada saat mereka tumbuh dewasa (Yuni dkk: 2014). Salah satu media pembelajaran yang dapat digunakan oleh guru adalah melalui simulasi berkendara lalu lintas. Media pembelajaran ini bersifat menarik sebab anak diajak bermain peran secara langsung. Disamping itu, media ini bersifat interaktif sehingga membuat siswa menjadi lebih aktif dan mandiri. Pada penelitian ini dikembangkan media pembelajaran rambu-rambu lalu lintas yang berfungsi sebagai pengenalan rambu-rambu lalu lintas, simulasi bagaimana menggunakan kendaraan dengan baik, dan games tentang rambu-rambu lalu lintas yang dapat menarik perhatian siswa.

\section{Media pembelajaran}

Media pembelajaran adalah segala sesuatu yang dapat digunakan untuk menyalurkan pesan (bahan pembelajaran) sehingga dapat merangsang perhatian, minat, pikiran, dan perasaan siswa dalam kegiatan belajar guna mencapai tujuan pembelajaran.

Pemakaian media pengajaran dalam proses belajar mengajar dapat membangkitkan keinginan minat yang baru, memberi motivasi dan rangsangan pada kegiatan belajar serta membawa pengaruh-pengaruh psikologis yang baik terhadap siswa.

Menurut Azhar (2002) manfaat media pembelajaran adalah sebagai berikut:

1. Proses pembelajaran menjadi lebih jelas dan menarik. Media dapat menampilkan informasi melalui suara, gambar, gerakan, dan warna, baik secara alami maupun manipulasi, sehingga membantu guru untuk menciptakan suasna belajar menjadi lebih hidup, tidak monoton, dan tidak membosankan.

2. Proses pembelajaran menjadi lebih interaktif.

3. Efisiensi dalam waktu dan tenaga. Dengan media, tujuan belajar akan lebih mudah terccapai secara maksimal dengan waktu dan tenaga seminimal mungkin. Guru tidak harus menjelaskan materi ajaran secara berulang-ulang, sebab sekali sajian menggunakan media, siswa akan lebih mudah memahami pelajaran.

4. Meningkatkan kualitas hasil belajar siswa. Media pembelajaran dapat membantu siswa menyerap materi belajar lebih mendalam dan utuh. Bila dengan mengajar informasi verbal dari guru saja, siswa kurang memahami pelajaran. Tetai jika diperkaya dengan kegiatan melihat, menyentuh, merasakan, dan mengalami sendiri melalui media, pemahaman siswa akan lebih baik.

Peran media dalam pembelajaran khususnya dalam pendidikan anak usia dini semakin penting, artinya mengingat perkembangan anak pada saat itu berada pada masa berpikir konkret. Dengan menggunakan media pembelajaran, informasi yang diperoleh anak usia dini dapat diterima atau diserap anak dengan baik dan diharapkan terjadi perubahan-perubahan perilaku berupa kemampuan-kemampuan dalam hal pengetahuan, sikap, dan keterampilannya.

\section{Rambu Lalu Lintas}

Menurut peraturan Menteri Perhubungan Nomor 13 tahun 2014, rambu lalu lintas adalah bagian perlengkapan jalan yang berupa lambing, huruf, angka, kalimat, dan atau perpaduan yang 
berfungsi sebagai peringatan, larangan, perintah, atau petunjuk bagi pengguna jalan. Ramburambu lalu lintas dapat dikelompokkan sebagai berikut :

a. Rambu Peringatan

Rambu yang memperingatkan adanya kondisi bahaya dan berpotensi bahaya agar para pengemudi berhati-hati dalam mengemudikan kendaraannya. Misalkan rambu yang menunjukkan adanya lintasan kereta api atau adanya persimpangan berbahaya bagi para pengemudi. Pada rambu peringatan ada bermacam-macam rambu, diantaranya persimpangan datar dengan lintasan kereta api berpintu, tikungan ke kiri, tikungan ke kanan, tikungan tajam ke kanan, banyak tikungan, pengarah tikungan ke kiri, banyak anak, banyak orang bersepeda.

b. Rambu Larangan

Rambu ini berfungsi untuk melarang penggunaan dan pergerakan lalu lintas tertentu. Misalkan :

- Rambu larangan berhenti

- Rambu larangan membunyikan isyarat suara

- Semua kendaraan dilarang lewat

c. Rambu Perintah

Rambu ini berfungsi untuk memerintahkan penggunaan dan pergerakan lalu lintas tertentu misalkan :

- Rambu perintah memasuki lajur yang ditunjuk

- Rambu batas maksimum kecepatan

- Rambu perintah bagi jenis kendaraan tertentu untuk melalui jalur dan atau jalur tertentu.

d. Rambu Petunjuk

Rambu petunjuk adalah rambu yang digunakan untuk menyatakan petunjuk mengenai jurusan, jalan, situasi, kota, tempat, pengaturan, fasilitas, dan lain-lain bagi pengguna jalan.

\section{Simulasi Berkendara}

Simulasi berkendara merupakan contoh bagaimana berkendara dengan baik. Anak memperagakan contoh simulasi berkendara, yaitu simulasi berkendara di tikungan, simulasi mengendarai mobil-mobilan dari kardus, simulasi dilarang parker, dan simulasi traffic light.

Jadi, media pembelajaran simulasi berkendara dan berlalu lintas melalui media barang bekas ini sangat bermanfaat apabila diajarkan kepada anak sejak usia dini. Karena selain melatih kedisplinan dalam belalu lintas, media ini dapat mengembangkan beberapa aspek seperti :

Aspek Nilai Agama dan Moral : Dalam aspek ini anak mengetahui cara berlalu lintas yang baik seperti tidak menyerobot jalur orang lain di jalan raya.

Aspek Sosial Emosional

Aspek Bahasa

Aspek Kognitif

Aspek Fisik Motorik
: Anak terbiasa berperilaku disiplin saat berlalu lintas dengan cara mematuhi rambu-rambu lalu lintas.

: Anak mampu memahami dan mengenal simbol-simbol huruf ataupun lambang pada rambu-rambu lalu lintas.

: Anak mengenal dan mampu menyebutkan arti dan simbol dari rambu-rambu lalu lintas.

: Anak terampil dalam menggerakkan tangan kanan dan kiri pada saat berperan sebagai pengendara dan polisi lalu lintas. 

lintas yang dibuat dari bahan bekas dan menggunting bentuk topi polisi.

\section{METODE PENELITIAN}

Penelitian ini dilaksanakan di TK Qilpi Al Jihad Surabaya. Sekolah ini terletak di Jalan Kejawan Putih Tambak Gang Masjid Nomer 1, Mulyosari - Surabaya. Penelitian ini dilaksanakan selama 4x yakni setiap sabtu 4 mei 2019, 11 mei 2019, 18 mei 2019 dan 25 mei 2019. Subjeknya adalah siswa TK B yang berjumlah 9 siswa laki-laki dan 5 siswa perempuan. Jenis penelitian ini adalah deskriptif kualitati karena metode yang digunakan untuk memecahkan masalah yang sedang dihadapi pada situasi sekarang (Ary: 1985, Azwar: 1999, Sukardi: 2004). Materi yang digunakan adalah mentaati tata tertib lalu lintas, saling menghormati antar pengendara, dan mengenal rambu-rambu lalu lintas. Sumber data yang digunakan adalah kegiatan murid ketika melakukan bermain peran dalam kegiatan simulasi berkendara. Sedangkan data yang diambil adalah hasil belajar siswa dengan menggunakan media bahan bekas.

\section{HASIL DAN DISKUSI}

Penelitian ini dilaksanakan selama 4x. Siswa selalu belajar tentang peraturan dan ramburambu lalu lintas setiap pertemuan. Setiap pertemuan mereka memainkan peran tentang simulasi berkendara. Setiap pertemuan mempunyai permainan tentang rambu-rambu lalu lintas yang berbeda, sehingga mereka lebih antusias dalam memahami rambu-rambu lalu lintas dan peraturan untuk berkendara. Untuk kegiatan dan hasil penelitian akan dijelaskan seperti di bawah ini.

Pada kegiatan awal, Guru mengajak anak bernyanyi dan bercerita tentang materi kegiatan hari ini, berdiskusi tentang macam-macam kendaraan darat, berdiskusi tentang mobil, menirukan gerakan mengemudikan mobil, dan mengenalkan kegiatan serta aturan yang digunakan dalam bermain lalu lintas.

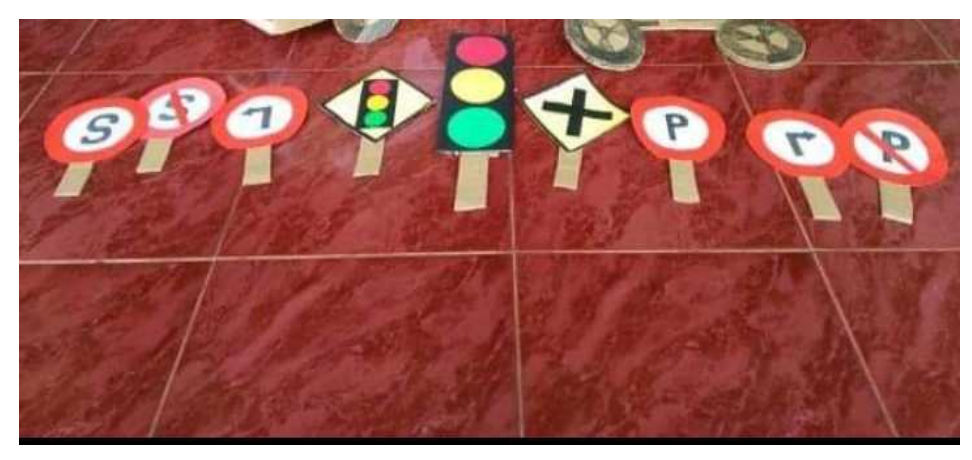

Gambar 1. Media Bahan Bekas Tentang Rambu-Rambu Lalu Lintas 


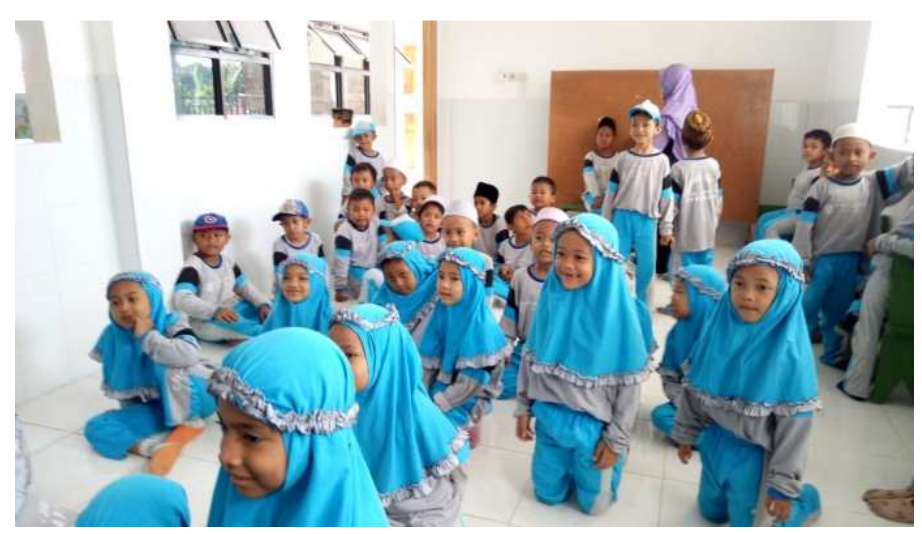

Gambar 2. Anak-anak Mendengarkan Cerita dan Penjelasan Tentang Materi Kegiatan

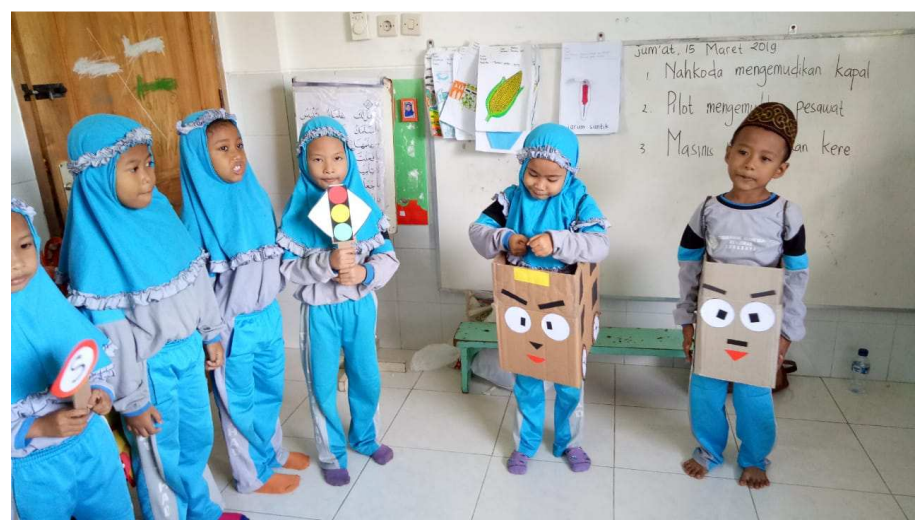

Gambar 3. Pengenalan Kegiatan Yang Digunakan Dalam Bermain Lalu Lintas

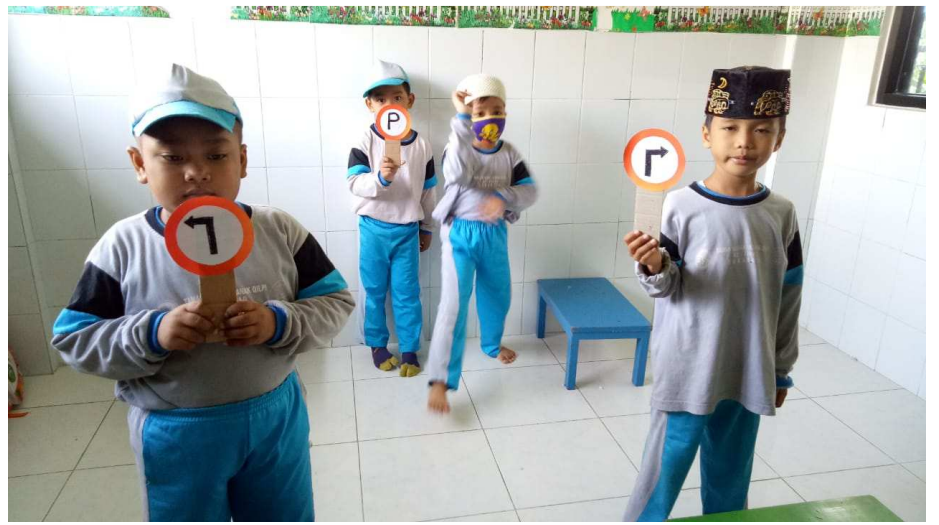

Gambar 4. Anak-Anak Mendengarkan Penjelasan Guru Mengenai Aturan Yang Digunakan Dalam Bermain Lalu Lintas

Selanjutnya kegiatan inti dari bermain simulasi lalu lintas ini, yaitu bermain mobilmobilan dan memperkenalkan berbagai jenis rambu-rambu lalu lintas. Anak diminta bermain peran mengendarai mobil dari kardus yang ditentukan guru, kemudian disepanjang perjalanan anak diminta menyebutkan rambu-rambu lalu lintas. Hal tersebut sangat penting untuk mengajarkan anak tertib dalam berlalu lintas sejak usia dini. 


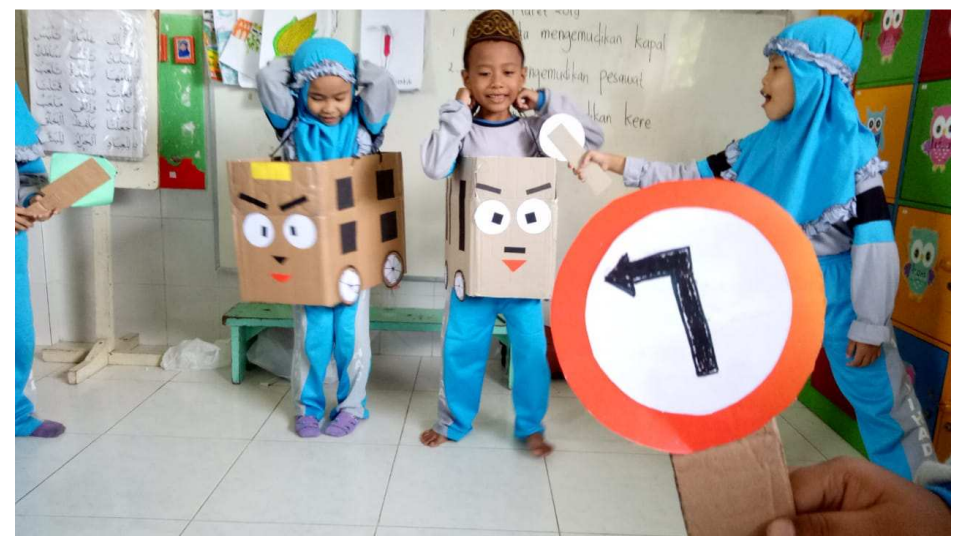

Gambar 5. Anak-Anak Bermain Simulasi Lalu Lintas

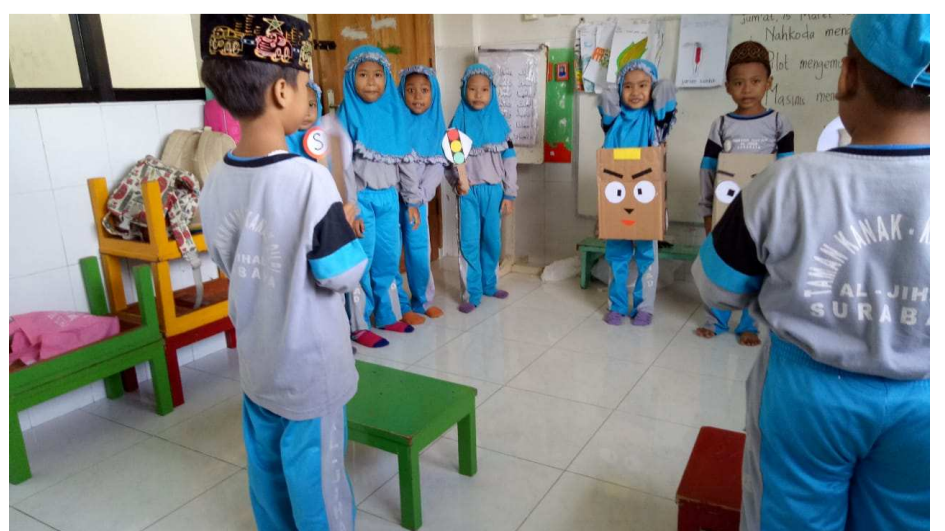

Gambar 6. Anak-Anak Bermain Peran Mengendarai Mobil

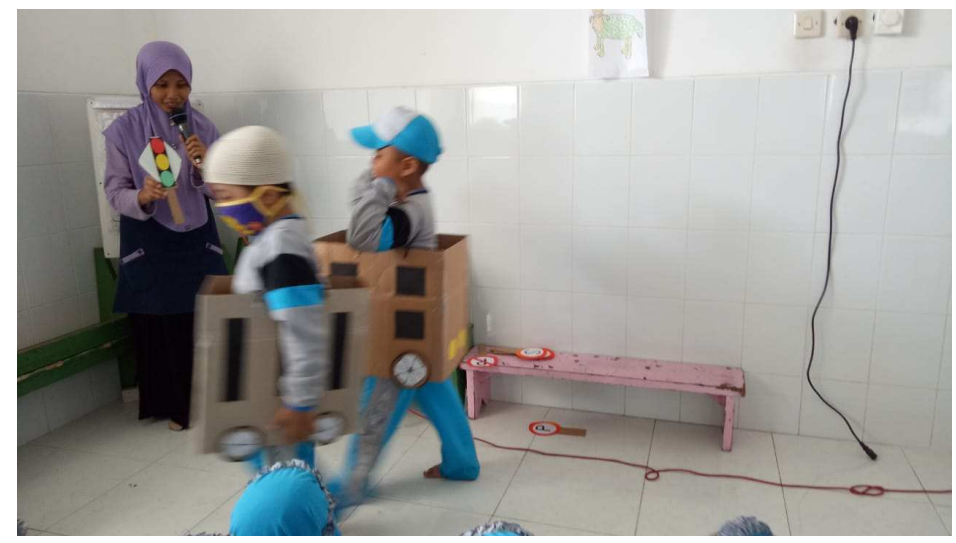

Gambar 7. Disepanjang Perjalanan Anak Menyebutkan Rambu-Rambu Lalu Lintas

Pada akhir kegiatan, guru menanyakan perasaannya selama hari ini. Bertanya jawab tentang materi pembelajaran hari ini. Berdiskusi tentang perasaan anak selama melakukan kegiatan bermain simulasi alat transportasi dengan mengenalkan rambu-rambu dan peraturan dalam berlalu lintas dengan baik dan benar, serta bercerita pendek yang berisi pesan-pesan. 


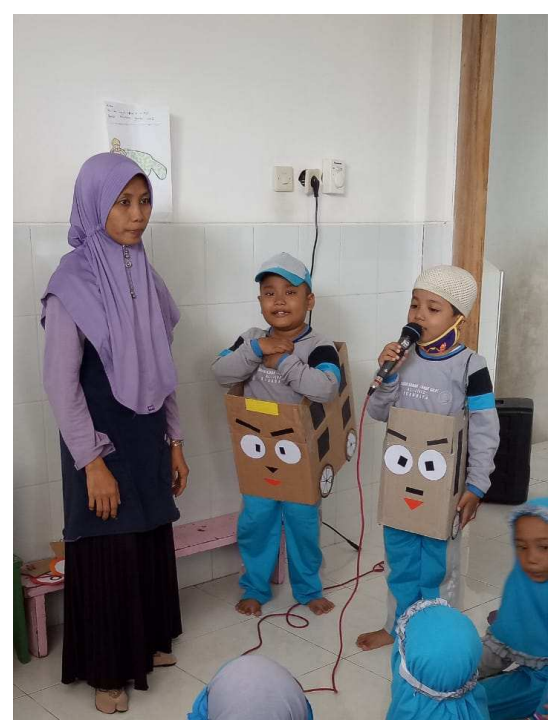

Gambar 8. Guru Menanyakan Perasaan Siswa Selama Hari Ini

Berdasarkan uraian kegiatan di atas, penulis menganalisa kelebihan dan kekurangan. Kelebihannya adalah bermanfaat untuk mengajarkan anak disiplin dan mematuhi peraturan lalu lintas, memanfaatkan barang bekas untuk media pembelajaran, serta memberikan semangat kepada anak dalam mengikuti kegiatan bermain. Sedangkan kekurangannya yaitu, kegiatan ini membutuhkan ruang kelas atau halaman yang luas, media cepat rusak, dan anak berebut ingin memainkan peran untuk mengemudikan mobil-mobilan.

\section{KESIMPULAN}

Pada dasarnya kecelakaan dalam berlalu lintas dapat berkurang apabila kita sadar dan tertib dalam berkendara serta mentaati peraturan lalu lintas. Disiplin dan tertib pada lalu lintas sudah selayaknya dikenalkan sejak usia dini agar kelak disaat mereka beranjak dewasa sudah mengerti dan memahami aturan-aturan berlalu lintas di jalan raya. Hal ini dilakukan pasalnya tidak sedikit nyawa yang melayang akibat tidak mematuhi rambu-rambu dan peraturan lalu lintas. Seperti menerobos lampu merah, palang pintu perlintasan kereta api, hingga melebihi batas kecepatan maksimum yang dianjurkan. Pengenalan peraturan dan rambu-rambu lalu lintas sangatlah penting, maka dari itu mengajarkan pada anak sejak dini diharapkan agar anak kelak menjadi generasi yang disiplin, tertib, dan memahami arti keselamatan.

\section{DAFTAR PUSTAKA}

Ary, Donald. 1985. Introduction to Research In Education. New York:CBS College Publishing

Azhar, A. 2002, Media Pembelajaran, Jakarta : Raya Grafindo Persada

Azwar, Saifuddin. 1999. Metode Penelitian. Yogyakarta : Pustaka Pelajar

Sukardi, 2004. Metode Penelitian Pendidikan. Jakarta: Bumi Aksara 
Yuni, Wiyarti, dan Gesang, Kristiyanto Nugoho. 2014. Pembangunan Media Pembelajaran Alat Transportasi Dan Rambu-Rambu Lalu Lintas Pada Taman Kanak-Kanak Pertiwi 1 Plumbungan Karangmalang Sragen. Journal Speed-Sentra Penelitian Engineering dan Edukasi, Vol.6 No.1 Hal.40-45 